Cite this: RSC Adv., 2014, 4, 21254

Received 18th January 2014

Accepted 8th March 2014

DOI: $10.1039 / \mathrm{c} 4 \mathrm{ra00526 \textrm {k }}$

www.rsc.org/advances

\title{
Prediction of the efficiency of diastereoisomer separation on the basis of the behaviour of enantiomeric mixtures
}

\begin{abstract}
Emese Pálovics, ${ }^{a}$ Zsolt Szeleczky, ${ }^{b}$ Balázs Födi, ${ }^{b}$ Ferenc Faigl ${ }^{\mathrm{ab}}$ and Elemér Fogassy ${ }^{\star b}$
The driving force of homo- and heterochiral complex formation in mixtures of chiral compounds is, probably, the effort of the system to separate the most symmetric associates from the less symmetric ones. A possible way to achieve separation of these associates is distribution between two phases. Therefore, during the separation of (a certain part) diastereoisomers similar trends can be observed as in the course of the distribution of enantiomeric mixtures between two phases, although in the first case a third chiral compound (namely the resolving agent) is present. Of course in this case the pursuit of symmetry is not so obvious as in case of enantiomeric mixtures. It should be noted that the outcome may thus be modified by the intervention of kinetic control. One can conclude that the structure of chiral compounds encodes the result of the (optical) resolution.
\end{abstract}

\section{Introduction}

In many cases, living organisms contain only one of the two enantiomers of chiral molecules, but often racemic compounds (1:1 mixture of the two enantiomers) are obtained in the chemical syntheses. The biological activity of enantiomers may be different or even opposite, so enantiomeric separations are necessary and inevitable. Many of the methods described in the literature for the separation of enantiomers involve the formation of diastereoisomers followed by liberation of the separated enantiomers. These enantiomeric separation methods are discussed and systematized in several articles. ${ }^{\mathbf{1 - 1 0}}$

In the course of the resolution processes, racemic compounds are reacted with another chiral reagent (resolving agent). The diastereoisomers so obtained are separated, and their decomposition affords the corresponding enantiomeric mixtures. Usually, pure enantiomers can only be obtained by further purification of these enantiomeric mixtures (Scheme 1).

The composition of the salt crystallized during the fractionated precipitation of the diastereoisomeric salts and enantiomeric mixtures is determined by the $\mathrm{SDE}^{\mathbf{1 1}}$ capacity (self disproportion of enantiomers) of the involved chiral compounds.

The most commonly used methods for the separation of enantiomeric mixtures are based on the exploitation of the distribution of hetero- and homochiral associates between two

${ }^{a}$ Research Group for Organic Chemical Technology, University of Technology and Economics, P.O.B. 91 Budapest, Budapest, H-1521, Hungary. E-mail: epalo@mail. bme.hu; Fax: +36 (1)4633648

${ }^{b}$ Department of Organic Chemistry and Technology, University of Technology and Economics, Budapest, Hungary phases (most often between solid and liquid or vapour phases). ${ }^{12}$ According to the most recent research enantiomeric enrichment can occur using achiral chromatography ${ }^{\mathbf{1 3 - 1 6}}$ and by separation of racemates using a chiral selector on an achiral ${ }^{17,18}$ stationary phase or chiral phase chromatography (HPLC), ${ }^{19}$ respectively.

A correlation between the eutectic composition of binary melting point diagrams of diastereoisomeric mixtures (ee EuDiast $)$ and efficiency of resolution $(F)$ was established by us (Scheme 2). ${ }^{20}$

Furthermore, it was found by analyzing the results of 45 resolutions, that the average enantiomeric purity $\left(\mathrm{ee}_{\mathrm{EuDia}}=\right.$ $78 \%$ ) of enantiomeric mixtures isolated from crystalline diastereoisomers correlates to the average value of the measured eutectic composition of the starting racemic compounds $\left(\mathrm{ee}_{\text {EuRac }}=73 \%\right)$. At the same time, when the eutectic composition of the resolving agent is higher than the eutectic composition of the racemic compound (in 29 cases), a better correlation was observed between the average value of enantiomeric purities $\left(\mathrm{ee}_{\mathrm{Dia}}=80 \%\right.$ ) of enantiomeric mixtures isolated from the crystalline diastereoisomers and the average value of eutectic compositions of enantiomeric mixtures of the resolving agent $\left(\mathrm{ee}_{\text {EuRes }}=78 \%\right)($ Table 1$) .{ }^{21}$

Based on these observations, we suppose that the composition of a crystalline diastereoisomer is determined either by the eutectic composition of the racemic compound or that of the resolving agent and the higher ee value has a more dominant effect (Scheme 3).

Consequently, a correlation can be found between the binary melting point/composition phase diagram of the diastereoisomeric mixtures and the phase diagrams of the enantiomers which are the constituents of the diastereoisomers. 

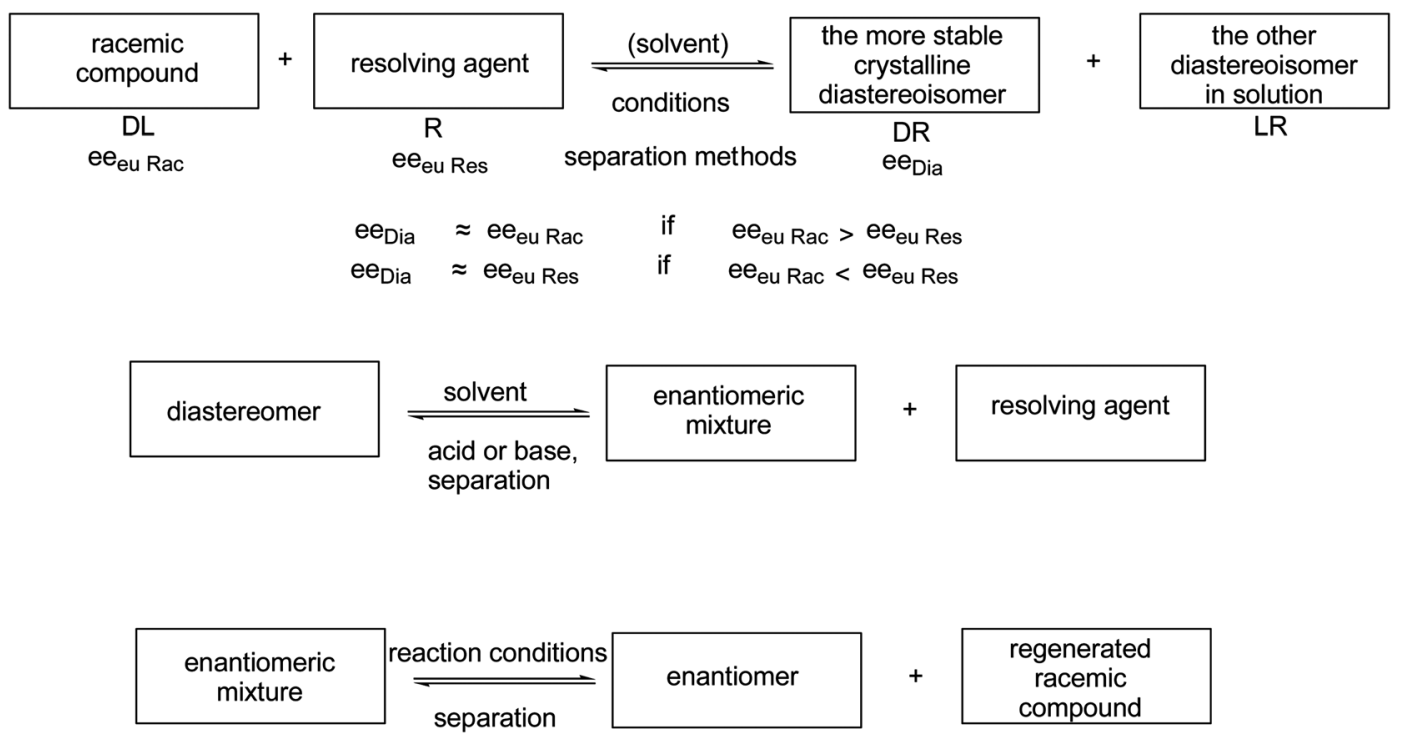

Scheme 1 General scheme for the preparation of pure enantiomers via diastereoisomeric salt formation (ee $e_{\text {euRac: }}$ ee of an enantiomer at the eutectic composition of the racemate; ee euRes: ee of the resolving agent enantiomer $(R$ or $\boldsymbol{A})$ at the eutectic composition; ee Dia $_{\text {: }}$ ee of the enantiomer of the original racemate at the eutectic composition of the diastereoisomeric salt).

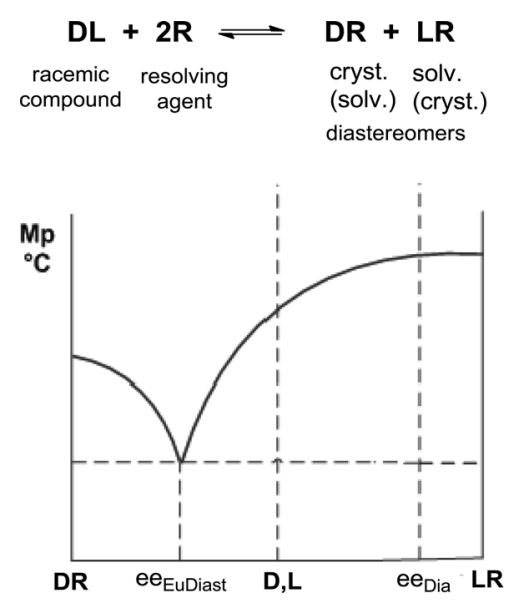

$$
\begin{aligned}
& F=e e_{\text {Dia }}{ }^{*} Y=\frac{1-2 e e_{\text {EuDiast }}}{1-e_{\text {EuDiast }}} \\
& \text { ee }_{\text {Dia: }} \text { eutectic composition } \simeq \begin{array}{l}
\text { the higher value of } \\
\text { ee }_{\text {EuRac }} \text { or ee }
\end{array} \\
& \text { Y: yield } \\
& F \text { : efficiency of resolution } \\
& \text { ee } e_{\text {EuDiast }} \text { : eutectic composition of diastereomeric mixture }
\end{aligned}
$$

Scheme 2 Melting point/composition diagram of diastereoisomers and the relation between eutectic composition of diastereoisomeric mixture and efficiency of resolution.

If we wish to separate the enantiomers of a racemic mixture using a structurally similar resolving agent (equivalent or half equivalent amount), the isomers of the racemic compound are transformed into "quasi enantiomeric mixtures". In the course of separation of these "quasi enantiomeric mixtures" (of diastereoisomers) the same methods based on the distribution between two phases can be used which are suitable methods for

Table 1 The average ee data of the investigated resolutions

\begin{tabular}{lllll}
\hline $\begin{array}{l}\text { Number of } \\
\text { resolutions }\end{array}$ & $\begin{array}{l}\text { ee } \\
\text { (average) } \%\end{array}$ & $\begin{array}{l}\text { ee } \\
\text { (averages }\end{array}$ & $\begin{array}{l}\text { ee } \\
\text { (avia }\end{array}$ & $\begin{array}{l}F \\
\text { (average) } \%\end{array}$ \\
\hline 45 & 73 & - & 78 & 0.57 \\
29 & - & 78 & 80 & 0.62
\end{tabular}

the separation of enantiomeric mixtures (also diastereoisomeric related supramolecular enantiomeric associates). ${ }^{7}$

\section{Separation of diastereoisomers from the melt}

The mixtures of racemic compounds and resolving agents can be considered as mixtures of diastereoisomeric supramolecular structures. These diastereomeric supramolecular structures exist in solutions and in melts, therefore these diastereoisomeric associates can be separated by crystallization from the melt. In this case the mixture of the racemic compound and the resolving agent is melted, then the crystalline phase - obtained by controlled cooling - can be separated by filtration (if it is possible). 

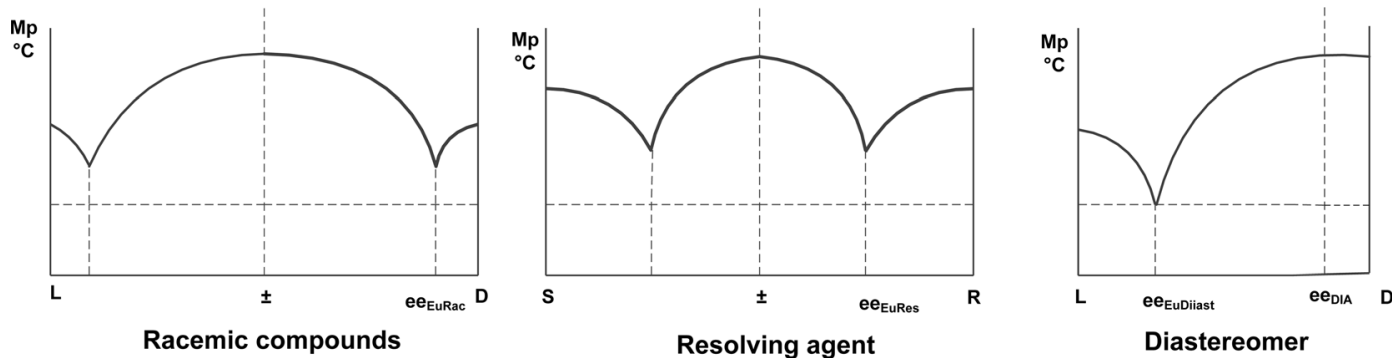

Scheme 3 The effect of the eutectic composition of racemic compound and resolving agent on the eutectic composition of diastereoisomers obtained (see also Scheme 2).

An example of such a separation is the crystallization of a diastereoisomeric mixture of MEN-DBTA molecular complex from a melt incorporating menthol (MEN) and $(R, R)$-dibenzoyltartaric acid $((R, R)$-DBTA) (Scheme 4$) .{ }^{22}$

It can be seen from the above example that the before mentioned behavior of mixed chiral compounds is valid not only for diastereoisomeric salts but for diastereoisomers in general. During resolution of racemic menthol with $(R, R)$-DBTA the parts of the diastereoisomeric complexes are kept together by weak second order interactions, only. Formation of the more stable molecular complex that crystallizes more quickly makes the separation possible.

\section{Separation of diastereoisomers by sublimation of enantiomeric mixtures}

Enantiomeric separations can be effectuated even if the mixture of diastereoisomers is obtained in a solid-solid reaction. An example is the reaction of solid 2-iodo-trans-cyclohexanol (ICH) and solid $(R, R)$-DBTA for three months (Scheme 5). It was observed in the course of the fractionated vacuum sublimation $^{23}$ of the above mentioned mixture of compounds, that one of the enantiomers of ICH sublimated as the first fraction at a relatively low temperature $\left(T_{1}\right.$, Scheme 5$)$, and the other ICH enantiomer sublimated at a higher temperature $\left(T_{2}\right)$, after thermal decomposition of the molecular complex formed previously in the solid-solid reaction.

\section{Separation of diastereoisomers by distillation of enantiomeric mixtures}

In the case of resolutions using half an equivalent of resolving agent it is expected, that the enantiomeric proportion of racemic compound may be separated from the corresponding diastereoisomer formed (distributed between two phases). In the reaction of methylanara (2-methylamino-1-phenylpropane, MA) and $(R, R)$-DBTA, after the precipitation of the diastereoisomeric salt, the residual free amin, namely $(S)$-MA could be obtained by distillation under vacuum, ${ }^{24}$ while the other enantiomer was obtained by the separation of the solid diastereoisomer residue (Scheme 6).

\section{Separation of diastereoisomers by fractionated distillation of enantiomeric mixtures}

This method is also suitable for fractionated separations if the resolving agent forms a salt that can decompose without any damage. An adequate example for this is the resolution of racemic anara (2-amino-1-phenilpropane, AN) by half an equivalent of the structurally related $(S)-N$-phthaloyl- $\alpha$-phenylethylamine (PPEA) (Scheme 7). Again, the free, optically active base ((R)-AN) could be distilled off at $T_{1}$, then the solid diastereoisomeric salt could be decomposed at a higher temperature ( $T_{2}$, by ring closure of the phthaloyl derivative), so the other amine enantiomer $((S)$-AN) could be distilled off in the second stage.

\section{Separation of diastereoisomers by extraction of enantiomeric mixtures with a supercritical fluid (carbon dioxide)}

In the course of a half equivalent resolution, the remaining free enantiomer may also be removed by extraction from the<smiles>CC1CCC(C(C)C)C(O)C1</smiles>

$(+)$-MEN<smiles>CC(C)C1CC[C@@H](C)C[C@H]1O</smiles>
$(-)-M E N$<smiles>O=C(O)C(C(=O)O)(C(=O)O)C(=O)O</smiles>

$(R, R)$-DBTA

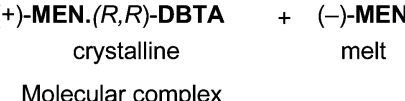

ee Dia: $: 83 \%$

Scheme 4 Separation from the melt. 


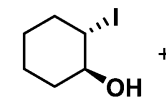

(士)-trans-ICH

\section{$+(R, R)$-DBBS \\ ee EuRes: $: 90 \%$

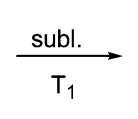
1. fraction
$\mathrm{ee}_{1}=\mathrm{ee}_{\text {Dia }}: 86 \%$ \\ $(1 R, 2 R)-\mathrm{ICH}+$ \\ F: 0.50}

$(1 S, 2 S)$-ICH. $(R, R)$-DBTA

Molecular complex

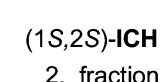

2. fraction

$\mathrm{ee}_{2}=\mathrm{ee}_{\mathrm{Dia}}: 80 \%$

$\mathrm{F}: 0.42$

Scheme 5 Separation of diastereoisomers by fractionated vacuum sublimation.

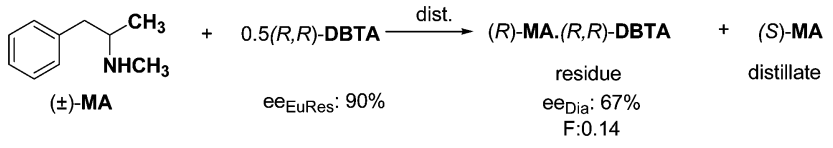

Scheme 6 Separation of diastereoisomers by distillation of an enantiomeric mixture.

reaction mixture after the crystallization of the diastereoisomeric salt. This extraction can be accomplished using a supercritical fluid, most often supercritical carbon dioxide. In case of resolution of trans-cyclohexane-1,2-diol (trans-CHD) ${ }^{25}$ by $(R, R)$ tartaric acid $((R, R)-\mathbf{T A})$ the free enantiomeric portion was separated by extraction with supercritical $\mathrm{CO}_{2}$ from the mixture of the excess of trans-CHD and the crystalline diastereoisomeric complex (Scheme 8). Of course, the other enantiomer can be recovered from the diastereoisomeric complex.

\section{Separation of diastereoisomeric molecular complexes by fractionated crystallization}

The above demonstrated methods can be applied for the separation of enantiomers having an asymmetric center on a phosphorous atom. For example, the resolution of several racemic alkyl-, alkoxy-, and aryl-substituted 3-methyl-3-phospholene oxides were accomplished via molecular complex formation with $\quad(R, R)$-TADDOL $\quad\left(\alpha, \alpha, \alpha^{\prime}, \alpha^{\prime}\right.$-tetraphenyl-1,3-dioxolan-4,5dimethanol) as the resolving agent (Scheme 9). If half an equivalent of $(R, R)$-TADDOL was used, the more stable diastereoisomer crystallized which could be isolated by conventional methods, such as filtration. ${ }^{26}$

\section{Separation of diastereoisomeric coordination complexes by fractionated crystallization}

In other cases, the cyclic $P$-chiral 3-phospholene oxides were separated into their enantiomeric mixtures by resolution with the $\mathrm{Ca}^{2+}$ or $\mathrm{Mg}^{2+}$ salts of DBTA (DBTC). As is shown in Scheme 10 , when half an equivalent of resolving agent was used, the favourable diastereoisomer was precipitated. After filtration and decomplexation of the diastereoisomeric complex, an enantiomeric mixture of the 3-phospholene oxide (MPO) was obtained. The antipode of the first isolated MPO enantiomer was recovered from the mother liquors of the resolutions. ${ }^{27}$ The effectiveness of the method was demonstrated on a series of cyclic $P$-chiral 3-phospholene oxides. ${ }^{28}$

\section{Separation of diastereoisomers from enantiomeric mixtures using mixtures of two immiscible solvents}

Based on the above examples, formation of solid phase, solidliquid phases or solid-gas phases systems is always necessary for the separation of diastereoisomers. Now the question is: could one achieve chiral separation between two immiscible liquid phases? The answer yes, of course. Diastereoisomers may be separated by distribution between two liquid phases (Scheme 11).

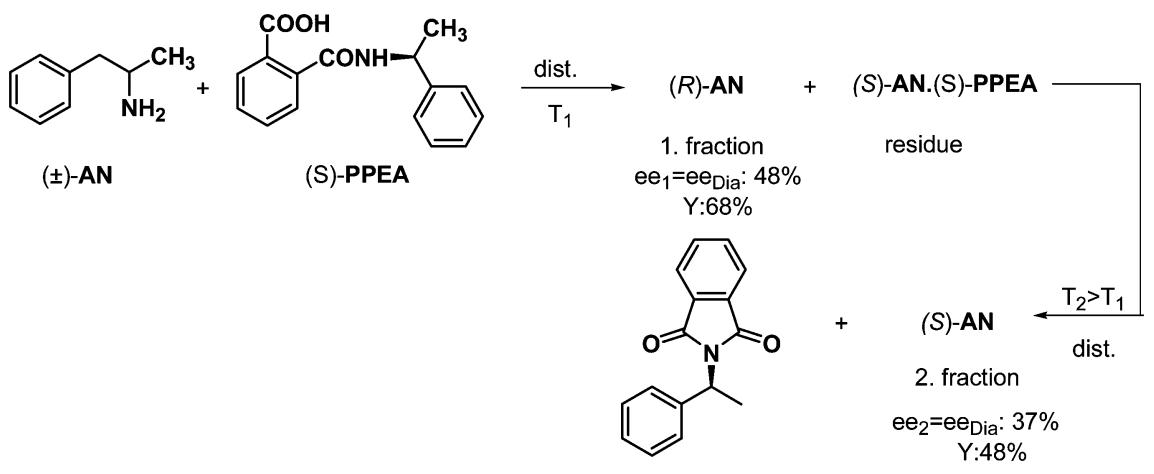

Scheme 7 Resolution of racemic AN via fractionated distillation of a mixture of free AN and AN (S)-PPEA diastereoisomeric salt. 


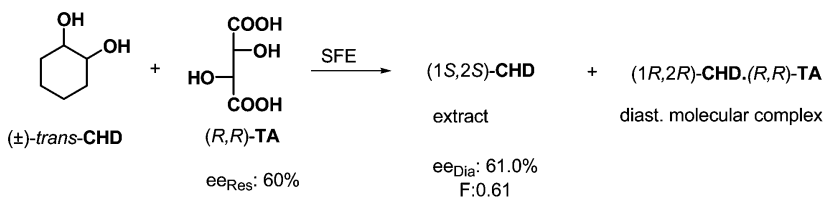

Scheme 8 Separation of the trans-CHD enantiomers via molecular complex formation followed with supercritical fluid extraction.

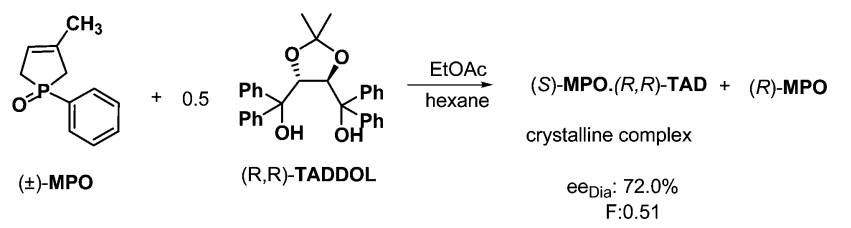

Scheme 9 Separation of diastereoisomeric molecular complexes of MPO by fractionated crystallization.

If the racemic methylanara (MA) is reacted with half an equivalent of sodium salt of $(R, R)$-tartaric acid $((R, R)$-TAN $)$ in a mixture of water and benzene, the enantiomer and diastereoisomer are distributed between the two liquid phases. $^{29}$

The aqueous phase contains the neutral salt of TAN-MA, while the other enantiomer can be found in the organic layer. So the separation of diastereoisomers or enantiomers can be accomplished without crystallization, using two immiscible solvents. The two solvent phases can also provide particularly good separation if the diastereoisomer can crystallize due to its insolubility in the applied two solvents.

\section{Separation of diastereoisomers by crystallization from two immiscible solvents}

The resolution of racemic grandaxine (GRA) with half an equivalent of DBTA in a mixture of water and chloroform, or water and dichloromethane is an example of the separation of diastereoisomers by crystallization from two immiscible solvents. ${ }^{30}$ The crystallization started at the boundary of the solvent phases, then it is accelerated. The formed diastereoisomeric salt was filtrated, and the two phases were separated. The enantiomeric mixture containing one of the enantiomers in excess was obtained from the diastereoisomeric

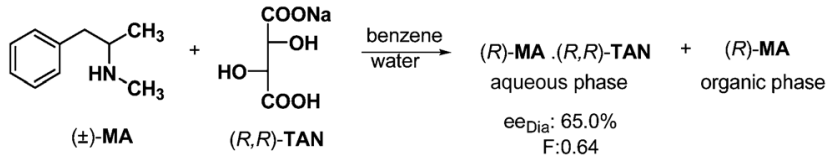

Scheme 11 Resolution of MA using two immiscible solvents.

salt, while the other enantiomer was recovered in neutral form from the organic phase. In addition, a small amount of GRA with racemic composition was isolated from the aqueous solution (Scheme 12). From the ee data shown in Scheme 12 one can conclude that in this case, the eutectic composition of the racemic compound governed the efficiency of separation.

\section{Separation of diastereoisomers by crystallization involving the formation of solvates}

It is very common during the separation of diastereoisomers, that the enantiomeric purity and yield of separation is increased when solvates were formed during the crystallization of the diastereoisomers. For example, if trans-chrysanthemic acid (CRS) is resolved with $N, N$-dimethyl-aminodiol (obtained by the transformation of an intermediate of chloramphenicol) in methanol, a methanol solvate of the diastereoisomer could be isolated in very good diastereoisomeric purity, but the yield was $52 \%$, only (Scheme 13). Whereas the resolution was accomplished in diisopropyl ether, or methyl isobutyl ether in the presence of methanol, the methanol solvate of the diastereoisomer was also crystallized, but both the purity and the yield increased significantly. ${ }^{31}$

\section{Separation of diastereoisomers by crystallization in the presence of a structurally related achiral reagent}

Frequently, the resolution can be accomplished only via solvation. In the previous example the resolution could be carried out using another solvent. When the racemic $\alpha$-phenylethylamine (PEA) was resolved using half an equivalent of a derivative of a PEA enantiomer, a diastereoisomer was isolated which contained $(S)$-PEA in 60\% excess in acetone (Scheme 14). ${ }^{32}$ When an achiral compound (such as urea) with a related structure to one

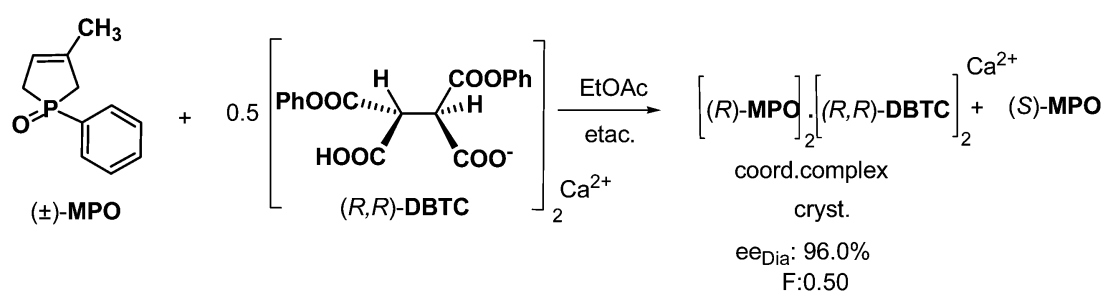

Scheme 10 Resolution of MPO via diastereoisomeric coordination complex formation and fractionated crystallization. 


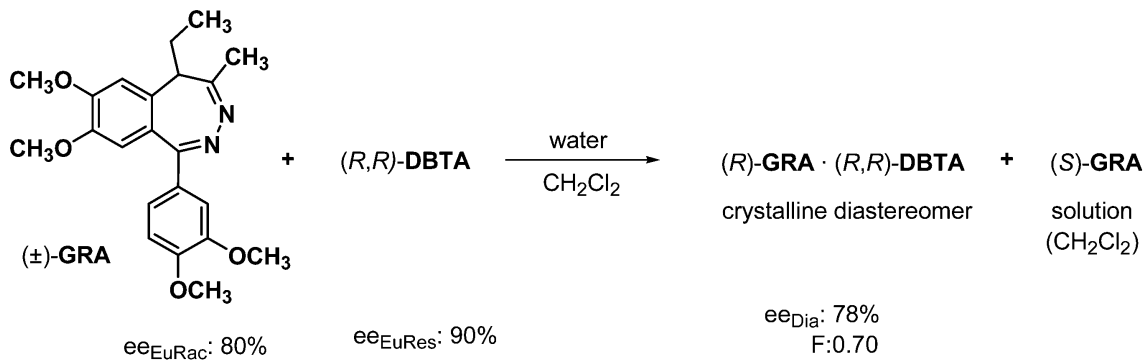

Scheme 12 The separation of diastereoisomers by crystallization from immiscible solvents.<smiles>CC(C)=CC1C(C(=O)O)C1(C)C</smiles>

$( \pm)$-trans-CRS

$e_{\text {EuRac }}: 70 \%$<smiles>CN(C)[C@H](CO)[C@H](O)c1ccc([N+](=O)[O-])cc1</smiles>

$(R, R)$-DAD

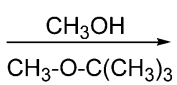

$(R)$-trans-CRS $\cdot(R, R)$-DAD $\cdot \mathrm{CH}_{3} \mathrm{OH}$

crystalline

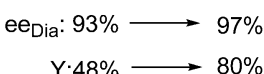

Scheme 13 Separation of diastereoisomers by crystallization involving the formation of solvates.

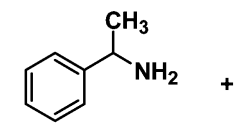

(士)-PEA

ee EuRac: $78 \%$<smiles>CC(NC(=O)CCCC(=O)O)c1ccccc1</smiles>

(R)-GPA

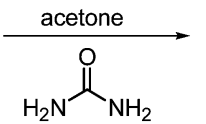

$\mathrm{H}_{2} \mathrm{~N}_{\mathrm{NH}_{2}}^{\mathrm{O}}$

(S)-PEA

crystalline diastereomer

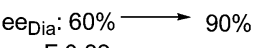

Scheme 14 Separation of diastereoisomers by crystallization involving the formation of solvates.

part of the resolving agent was added to the solution before crystallization, much purer diastereoisomer was isolated with an $(S)$-PEA enantiomeric excess of $90 \%$.

So the achiral solvate forming reagent - which is structurally related to either the resolving agent or the racemic compound promoted the crystallization of the diastereomer, and increased enantiomeric excess of the diastereomer.

\section{Crystallization of diastereoisomers based on kinetic and thermodynamic control}

The decisive role of kinetic and thermodynamic control was observed in the separation of enantiomeric mixtures. This

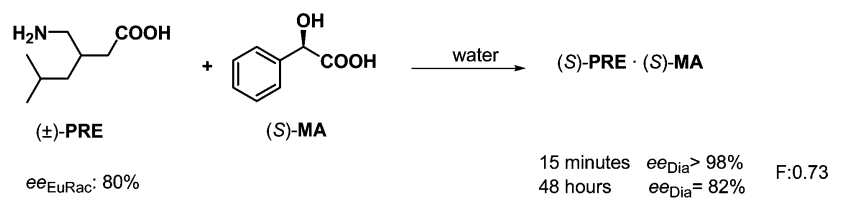

Scheme 15 The effect of kinetic control on the separation of diastereoisomers. phenomenon can also be found for both the separation of quasi-enantiomeric mixtures and conventional resolutions. $^{33,34}$ For example, the effect of kinetic control was observed in the resolution of pregabalin (PRE) by mandelic acid (S)-MA (Scheme 15). When the crystalline diastereoisomeric salt was isolated after 15 minutes crystallization, the enantiomeric excess of $(S)$-PRE isolated from the salt was $98 \%$, while the ee decreased significantly if the crystallization was carried out over 48 hours.

This means that the thermodynamic control has a disadvantageous effect on this process. The same phenomenon was observed in the course of the reciprocal process, when racemic MA was resolved by $(S)$-PRE. Namely, crystallization of the diastereoisomeric salt was controlled kinetically.

In other cases it is necessary to wait until thermodynamic equilibration, because in these cases the process is controlled thermodynamically. An adequate example is the resolution of an intermediate of tamsulozin (TAM) with $(R, R)$ DBTA (Scheme 16). In this case the diastereoisomeric salt contained the $(R)$-TAM enantiomer in excess. However, after an hour of crystallization, practically racemic TAM was found in the salt, but excellent enantiomeric excess could be achieved when the diastereoisomer was crystallized for 48 hours. ${ }^{35}$ 


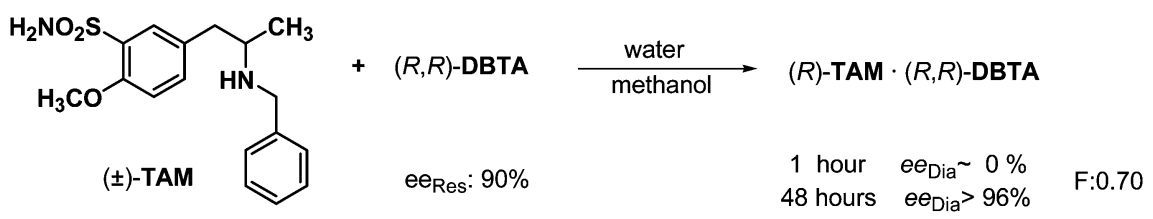

Scheme 16 The effect of thermodynamic control on the separation of diastereoisomers.

Table 2 The average ee data of the examined resolutions

\begin{tabular}{llll}
\hline $\begin{array}{l}\text { No. of } \\
\text { experiments }\end{array}$ & $\begin{array}{l}\text { Average value } \\
\text { of ee } \text { EuRac }_{\text {ee }} / \mathrm{euRes}^{b}\end{array}$ & $\begin{array}{l}\text { Average value } \\
\text { of ee }{ }_{\text {Dia }} b\end{array}$ & $\begin{array}{l}\text { Average } \\
\text { value of } F\end{array}$ \\
\hline $13\left(10^{a}\right)$ & $80 \%$ & $78 \%$ & 0.62
\end{tabular}

${ }^{a}$ The used compounds are not structurally related. ${ }^{b}$ ee $_{\text {eurac }}$ : ee of an enantiomer at the eutectic composition of the racemate; $e_{\text {EuRes: }}$ ee of a resolving agent enantiomer $(R$ or $\boldsymbol{S})$ at the eutectic composition; $e_{\text {Dia }}$ : ee of an enantiomer of the original racemate at the eutectic composition of the diastereoisomeric salt.

\section{Conclusion}

The above mentioned examples demonstrate that the properties of the involved enantiomeric mixtures determine the enantiomer (diastereoisomer) distribution between two phases and in this way the behaviour of the chiral compounds used determines the efficiency of the process during enantiomer or diastereoisomer separations. There are numerous methods of choice (solid-solid, solid-liquid, solid-gas, liquid-liquid distributions) and, of course, we should choose the most favourable method (if there is more than one possibility).

We have recognized that in the resolution processes the diastereoisomers behave similarly to their constituent enantiomeric mixtures if the resolving agent was structurally related to the racemic compound.

We demonstrated that the eutectic composition of the racemate and/or the resolving agent determines the composition of the formed (crystalline) diastereoisomers even if the diastereoisomer forming chiral compounds are not structurally similar. Comparison of the average ee values of the obtained enantiomeric mixtures from series of resolutions with the average eutectic compositions of the involved chiral compounds (racemate and resolving agent) confirmed the above observation, namely the higher eutectic composition governs the enantiomer separation (Table 2).

We also think that the eutectic composition of the diastereoisomer forming enantiomers determines the efficiency of the resolutions in cases of crystalline diastereoisomeric salt, molecular- or coordination complex formations and these governing effects are valid when the separation is based on the distribution between two liquid phases.

\section{Acknowledgements}

The authors are grateful for the financial support of the Hungarian Scientific Research Found (OTKA grant number K
104769 for E. Fogassy and K 104528 for F. Faigl) of the New Széchenyi Development Plan (TÁMOP-4.2.1/B-09/1/KMR-20100002) and to Gedeon Richter Plc. for the Gedeon Richter PhD Scholarship (Zs. Szeleczky).

\section{References}

1 P. Newman, Optical resolution procedures of chiral compounds 1-3, Resolution Information Center, New York, 1978-1984.

2 S. H. Wilen, Topics in Stereochemistry, ed. E. L. Eliel and N. L. Allinger, Wiley-Interscience, New York, 1972, vol. 6, p. 107.

3 J. Jaques, S. H. Wilen and A. Collet, Enantiomers Racemates and Resolution, Wiley-Interscience, New York, 1981.

4 F. Faigl and D. Kozma, Enantiomer Separation: Fundamentals and Practical Methods, ed. F. Toda, Kluwer Academic Press, Dordrecht, 2004, p. 73.

5 E. Fogassy, M. Nógrádi, E. Pálovics and J. Schindler, Synthesis, 2005, 10, 1555.

6 E. Fogassy, M. Nógrádi, D. Kozma, G. Egri, E. Pálovics and V. Kiss, Org. Biomol. Chem., 2006, 16, 3011.

7 F. Faigl, E. Fogassy, M. Nógrádi, E. Pálovics and J. Schindler, Tetrahedron: Asymmetry, 2008, 4, 519.

8 R. A. Sheldon, Chirotechnology, Marcel Dekker Inc, New York, 1993.

9 S. H. Wilen, A. Collet and J. Jaques, Tetrahedron, 1977, 33, 2725.

10 Y. Kobayash, K. Kodama and K. Saigo, Org. Lett., 2004, 17, 2941.

11 V. A. Soloshonok, Angew. Chem., Int. Ed., 2006, 45, 766.

12 F. Faigl, E. Fogassy, M. Nógrádi, E. Pálovics and J. Schindler, Org. Biomol. Chem., 2010, 8, 947-959.

13 J. Martens and R. Bhushan, J. Liq. Chromatogr., 1992, 15, 1-27. 14 T. Nakamura, K. Tateishi, S. Tsukagoshi, S. Hashimoto, S. Watanabe, V. A. Soloshonok, J. L. Aceña and O. Kitagawa, Tetrahedron, 2012, 68, 4013-4017.

15 A. E. Sorochinsky, T. Katagiri, T. Ono, A. Wzorek, J. L. Aceña and V. A. Soloshonok, Chirality, 2013, 25, 365-368.

16 V. A. Soloshonok and D. O. Berasov, Chem. Today, 2008, 24, 44.

17 K. Günther, J. Martens and M. Schickedanz, Angew. Chem., Int. Ed. Engl., 1984, 23, 506.

18 K. Tateishi, S. Tsukagoshi, T. Nakamura, S. Watanabe, V. A. Soloshonok and O. Kitagawa, Tetrahedron Lett., 2013, 54, 5220-5223.

19 A. M. Krstulović, Chiral Separations by HPLC, Ellis Horwood, 1989, p. 548.

20 D. Kozma, Gy. Pokol and M. Ács, J. Chem. Soc., Perkin Trans. 2, 1992, 435 . 
21 E. Pálovics, Zs. Szeleczky, F. Faigl and E. Fogassy, New trends and strategies in the chemistry of advanced materials, ed. S. G. Muntean and R. Tudose, 2013, p. 74.

22 K. Simon, Z. Vincze, K. Marthi, G. Lévai, Gy. Pokol, E. Fogassy and D. Kozma, J. Therm. Anal. Calorim., 2004, 75, 787.

23 Cs. Kassai, D. Kozma and E. Fogassy, Synth. Commun., 2006, 36, 1015.

24 M. Ács, A. Mravik, E. Fogassy and Zs. Böcskei, Chirality, 1994, 6, 314 .

25 P. Molnár, P. Thörey, Gy. Bánsághi, E. Székely, L. Poppe, A. Tomin, S. Kemény, E. Fogassy and B. Simándi, Tetrahedron: Asymmetry, 2008, 19, 1587.

26 T. Novák, J. Schindler, V. Ujj, M. Czugler, E. Fogassy and Gy. Keglevich, Tetrahedron: Asymmetry, 2006, 17, 2599.

27 V. Ujj, J. Schindler, T. Novák, M. Czugler, E. Fogassy and Gy. Keglevich, Tetrahedron: Asymmetry, 2008, 19, 1973.
28 P. Bagi, E. Fogassy and Gy. Keglevich, Hung. Pat. Appl. 1200228, 2012.

29 M. Ács, D. Kozma and E. Fogassy, ACH - Models Chem., 1995, 132, 475.

30 E. Fogassy, G. Tóth, K. Simon, T. Láng, L. Ladányi and L. Párkányi, J. Mol. Struct., 1978, 147, 143.

31 M. Ács, D. Kozma, É. Kozsda, Gy. Keserü, Zs. Böcskei, J. Szilágyi, K. Simon, B. Bertók and E. Fogassy, J. Chem. Soc., Perkin Trans. 2, 2000, 149.

32 J. Schindler, M. Egressy, L. Bereczki, Gy. Pokol, E. Fogassy and K. Marthi, Chirality, 2007, 19, 239.

33 J. Neu, E. Fogassy, N. Szalma, P. Kálvin, J. Schindler, G. Jakab, S. Garadnay and E. Pálovics, Hung. Pat. Appl. 1000186, 2010.

34 E. Fogassy, E. Pálovics and Zs. Szeleczky, Hung. Pat. Appl. 1200227, 2012.

35 T. Gizur, J. Törley, E. Fogassy, G. Egri, J. Bálint and Á. Demeter, Hung. Pat. 202963, 2002. 